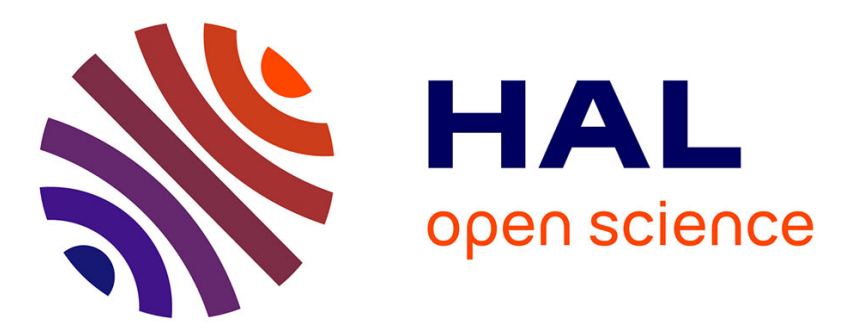

\title{
Beware of the Flory parameter to characterize polymer-polymer interactions: A critical reexamination of the experimental literature
}

Guillaume Miquelard-Garnier, Sébastien Roland

\section{- To cite this version:}

Guillaume Miquelard-Garnier, Sébastien Roland. Beware of the Flory parameter to characterize polymer-polymer interactions: A critical reexamination of the experimental literature. European Polymer Journal, 2016, 84, pp.111-124. 10.1016/j.eurpolymj.2016.09.009 hal-02271688

\section{HAL Id: hal-02271688 \\ https://hal.science/hal-02271688}

Submitted on 27 Aug 2019

HAL is a multi-disciplinary open access archive for the deposit and dissemination of scientific research documents, whether they are published or not. The documents may come from teaching and research institutions in France or abroad, or from public or private research centers.
L'archive ouverte pluridisciplinaire $\mathbf{H A L}$, est destinée au dépôt et à la diffusion de documents scientifiques de niveau recherche, publiés ou non, émanant des établissements d'enseignement et de recherche français ou étrangers, des laboratoires publics ou privés. 


\title{
Macromolecular Nanotechnology - Review \\ Beware of the Flory parameter to characterize polymer-polymer interactions: A critical reexamination of the experimental literature
}

\author{
Guillaume Miquelard-Garnier*, Sébastien Roland \\ PIMM, ENSAM/CNRS/CNAM, UMR 8006, 151 boulevard de l'Hôpital, 75013 Paris, France
}

\begin{abstract}
A B S T R A C T
Methods for obtaining Flory parameter $(\chi)$ values for polymer blends or blocks are critically examined, for three simple systems (polystyrene/poly(methyl methacrylate), polystyrene/polycarbonate, poly(methyl methacrylate)/polycarbonate). In particular, uncertainties for calculated and experimental values are discussed and compared. Data obtained using scattering measurements combined with a mean-field analysis are reexamined. We show that different experimental techniques will lead to significantly different $\chi$ values for a given system, and that even for one experimental technique, the uncertainty on molecular parameters used to fit the data may impact the extracted value for $\chi$. We also show that, though frequently used in the literature, $\chi$ values obtained via solubility parameters should not be used for any quantitative analysis of polymer-polymer interactions. This shows that the Flory parameter may not be relevant when discussing small effects on vague notions such as compatibility between polymers, or should at least be used with caution.
\end{abstract}

\section{Interaction parameter}

Block copolymers

Polymer blends

Immiscibility

Compatibility

\section{Contents}

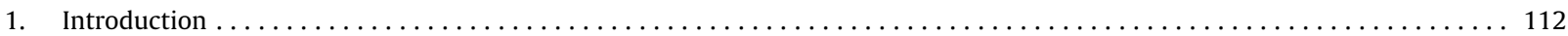

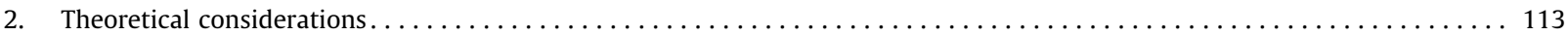

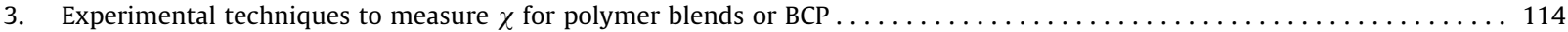

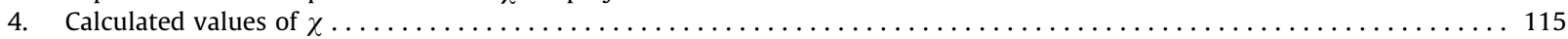

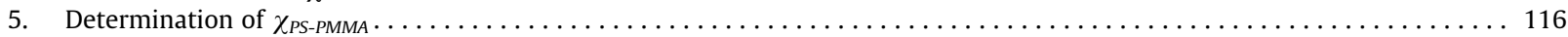

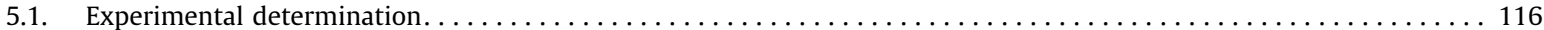

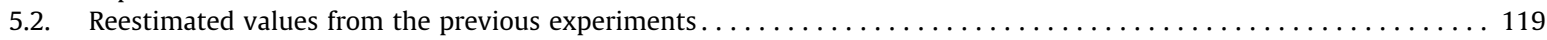

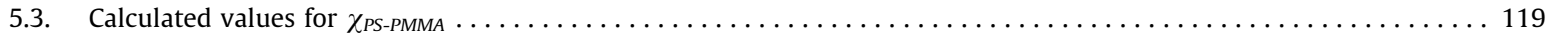

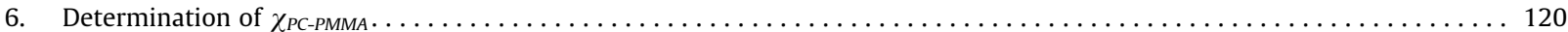

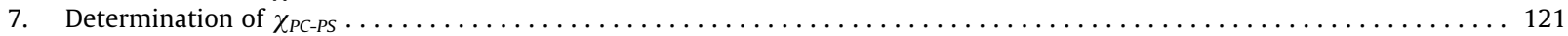

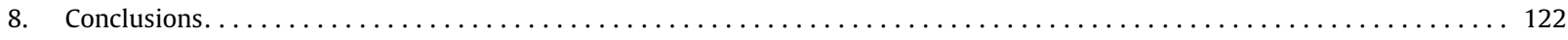

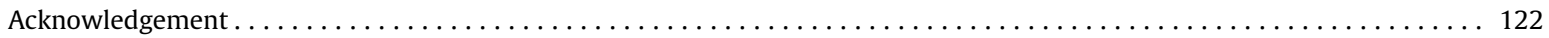

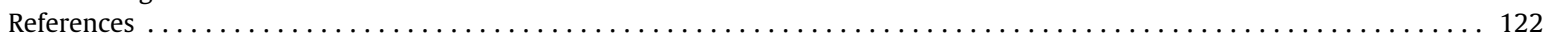

\footnotetext{
* Corresponding author.

E-mail address: guillaume.miquelardgarnier@lecnam.net (G. Miquelard-Garnier).
} 


\section{Introduction}

The free energy of mixing of two polymers is mainly governed by the energy of mixing (because of the degree of polymerization of polymers, the entropic term in the free energy is usually very small). The energy of mixing depends on a parameter characterizing the interactions between polymers which has been called the Flory-Huggins interaction parameter and is usually noted $\chi[1]$.

As a first approximation, polymers are miscible with each other at given temperature and composition (i.e. the domain sizes of their mixture will be comparable to the dimension of the monomers) only when this parameter is negative. For such blends (for example polystyrene/poly(vinyl methyl ether)), $\chi$ will only be negative for certain temperatures: below (lower critical solution temperature - LCST - systems), above (upper critical solution temperature - UCST - systems) a certain temperature, or in a range of temperatures (systems displaying both LCST and UCST) [2].

However, most polymers are immiscible with each other, which means they will undergo phase separation when blended together. In these cases $\chi$ is positive [1,2]. Jones and Randal [2] distinguish between immiscible polymers displaying very similar polymer pairs (for example polymers differing by isotopic substitution) and having $\chi$ on the order or below $10^{-4}$ and the vast majority of blends, when no close similarity nor specific interactions between the polymers lead to $\chi$ values in the $10^{-3}-10^{-1}$ range.

For a given blend, the Flory-Huggins parameter depends on the temperature, but also, though this is not apparent in the Flory-Huggins theory, on other parameters such as the volume fraction of the polymers, their degree of polymerization and even their dispersity, tacticity or pressure. In consequence two polymers can be miscible over a certain composition range, for certain molar masses (usually low molar masses), or under certain conditions of flows [3] or pressure. These systems are usually called partially miscible. A more indistinct notion often used, especially in the field of polymer engineering, is the notion of "compatibility" for immiscible blends with some interactions/interphase between the phases (and, in consequence, potentially interesting performances as a material) [1].

It is also well known that polymers can display physical properties (glass transition temperature, storage and loss moduli, ability to crystallize...) that differ significantly from those of the bulk when confined at nanometric scales (i.e. sizes comparable to the radius of gyration of the macromolecules) [4-6]. Hence, the ability to control the structure of polymeric materials (especially those constituted of two or more polymers) down to the nanoscale might have a tremendous impact for many engineering applications and for the design of materials exhibiting unique properties [7].

In this "engineering" context, being able to measure or calculate accurately the Flory interaction parameter between polymers is of great importance.

For example, block copolymers (BCP) with high Flory interaction parameters have been synthesized over the past few years to challenge the photolithography limit reached in the nanoelectronics industry $[8,9]$. To further decrease the size of the domain periodicity below $10 \mathrm{~nm}$, low molar mass (represented by the degree of polymerization $N$ ) block copolymer can advantageously be used since they offer self-assembled features at these scales. However, the incompatibility of the blocks (as quantified by $\chi$ ) must be chosen high enough so that the degree of segregation $(\chi N)$ of the blocks is above the segregation limit, meaning that the block copolymer is still microphase separated. $\chi$ is then a crucial measurement to characterize the ability of the block copolymer to produce smaller periodic domains.

Another example consists in the development of nanoblends or in other words polymer blends with nanophases which can display unusual properties (sometimes as simple as transparency) [7]. Usually, to achieve these morphologies, new processing methods have been developed, such as reactive blending [10] or multilayer coextrusion [6]. When the size of the dispersed phase is decreased, the surface-to-volume ratio increases and so does the contact surface and the intermolecular interactions at the interface, leading to a higher degree of interphase in the system. As will be detailed below, the typical size for this interphase is directly related to the Flory interaction parameter between the two blended polymers.

Thus, we want to illustrate in this article that, despite emerging from a quite simple formalism (which appears quite robust when one deals with polymer solutions instead of blends [11]), the Flory interaction parameter might be a more dangerous tool than expected when used to compare quantitatively, in terms of miscibility or compatibility, different polymer blends or BCP.

Tambasco [12] already showed that for partially miscible blends, similar values of $\chi$ may give rise to very different behaviors in terms of phase separation while polymer blends with similar chemical species and critical behavior can display very different values for $\chi$.

Elaborating on this, we want to specifically raise here the difficulty of obtaining a precise value for $\chi$ for a given blend and using it with confidence, especially to compare it with other blends. Whether measured experimentally, calculated via semiempirical equations or using numerical simulations, the uncertainty on its value can be much higher than a decade and probably no less than a factor of 2 , which will of course highly impact the data interpretation and must imply some caution when doing so. After a brief summary of the theoretical and experimental methods to obtain the Flory interaction parameter for blends or BCPs, a case study will be performed on three typical amorphous polymers immiscible with each other and their blends, polystyrene (PS), (atactic) poly(methyl methacrylate) (PMMA) and (bisphenol A) polycarbonate (PC) (see Fig. 1). Other behaviors for blends involving isotactic PMMA (miscible with PC) or (for example) tetramethyl-bisphenol A-PC (miscible with PMMA) will not be discussed here $[13,14]$ but they prove that slight changes in chemical structures (such as tacticity) can also drastically affect $\chi$. 

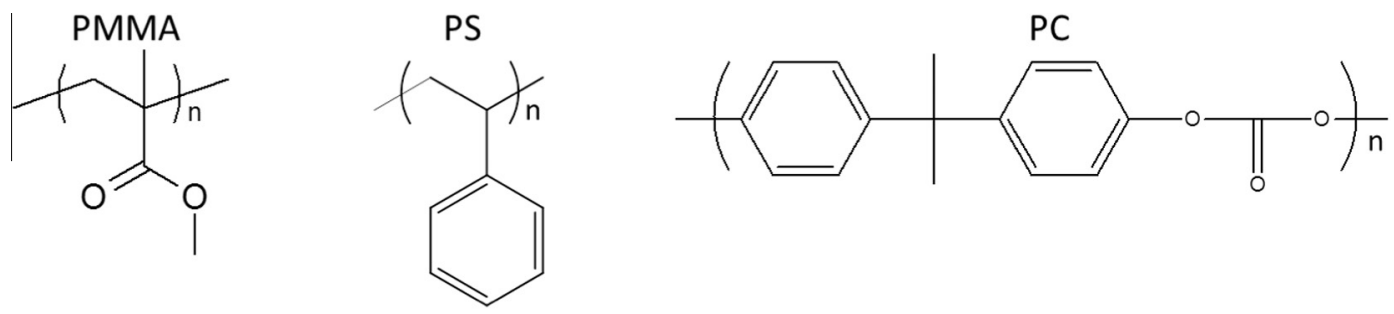

Fig. 1. Chemical structures for PMMA, PS and PC.

\section{Theoretical considerations}

The free energy of mixing of a polymer blend of two polymers A and B involves an entropic term which favors the mixing, and an energetic term, which can either promote or oppose the mixing. In the Flory-Huggins theory framework (mean-field description based on a lattice model which neglects the chain connectivity, with a mixing at constant volume), this energy of mixing can be expressed as a function of the pairwise (or segment-segment) interaction energies [15-17].

$$
\overline{\Delta F_{\text {mixing }}}=\overline{\Delta U_{\text {mixing }}}-T \overline{\Delta S_{\text {mixing }}}=k_{B} T\left(\frac{\Phi}{N_{A}} \ln \Phi+\frac{1-\Phi}{N_{B}} \ln (1-\Phi)+\chi \Phi(1-\Phi)\right)
$$

where $\overline{\Delta F_{\text {mixing }}}$ is the free energy of mixing per lattice site, $\overline{\Delta U_{\text {mixing }}}$ and $\overline{\Delta S_{\text {mixing }}}$ are the energy of mixing and the entropy of mixing respectively, with $k_{B}$ the Boltzmann constant and $T$ the temperature.

In Eq. (1), we have:

$$
\overline{\Delta S_{\text {mixing }}}=-k_{B}\left(\frac{\Phi}{N_{A}} \ln \Phi+\frac{1-\Phi}{N_{B}} \ln (1-\Phi)\right)
$$

with $\phi_{A}=\phi$ the volume fraction of the polymer $\mathrm{A}$ and $\phi_{B}=1-\phi$ the volume fraction of the polymer B, $N_{A}$ and $N_{B}$ the numbers of lattice sites occupied by molecules of $A$ and B, respectively (i.e. roughly the number of Kuhn monomers within a polymer chain, the volume of an individual lattice being taken equal to the volume of one Kuhn monomer and supposing the volume of Kuhn monomers are equals for the two polymers). As stated in the introduction, the entropic term, which always favors the mixing, is usually very small in the case of polymer blends, since $N_{A}$ and $N_{B}$ are large.

And

$$
\overline{\Delta U_{\text {mixing }}}=k_{B} T \chi \Phi(1-\Phi)
$$

$\chi$ being the Flory interaction parameter ( $\chi$ will be used later on for $\chi_{A B}$ unless otherwise specified), defined to characterize the difference of interaction energies in the blend.

$\chi$ can be expressed as a function of the three pairwise interactions energies between adjacent lattice sites in the system, i.e. $u_{A A}, u_{B B}$, and $u_{A B}$ and the coordination number of the lattice, $z$ :

$$
\chi=\frac{z}{2} \frac{\left(2 u_{A B}-u_{A A}-u_{B B}\right)}{k_{B} T}
$$

This parameter is dimensionless and compares the interaction between species within the A-B blend with the ones in the pure components. In most cases for polymer blends, the Flory interaction parameter is positive. If it is higher than the critical interaction parameter $\chi_{c}$, equal to $\chi_{c}=\frac{1}{2}\left(\frac{1}{\Phi N_{A}}+\frac{1}{(1-\Phi) N_{B}}\right)$ which is a very small number, on the order of $10^{-2}-10^{-3}$ for symmetric blends of polymers with typical molar masses around 100,000 g/mol), then the blend will phase separate over some composition range. For very small polymer chains however, the blend may become miscible.

As stated above, the Flory-Huggins theory is based on a mean-field approximation of a lattice model. In consequence, it neglects (or ignores) several aspects of real blends that can play a role in miscibility, such as blend compressibility, blend composition, chain rigidity, and also differences in monomer chemical structures, shapes, sizes and bonds [18-20]. The effects they might have on the measured values of the interaction parameter will be discussed in the experimental section of the article.

It should be noted that several alternate, more refined theories, have been developed over the years in an attempt to describe more accurately the behavior of polymer solutions or blends, by taking into account part of these parameters, especially compressibility [21-24]. However, their complexity has made them generally difficult to use in practice and they will not be discussed in details here, even though this is still a lively field of research (chain rigidity [25,26]). We will here only mention a recent and quite simple development by Douglas and Bosse [27] based on the lattice cluster theory developed by Freed and Dudowicz [22]. In this model, the free energy of mixing and hence the interaction parameter can be expressed as an infinite series of virial coefficients which reduces to the Flory-Huggins theory when truncating the series at the second virial coefficient, and to the lattice cluster theory at the third virial coefficient. Since second and third virial coefficients could 
be, though not quite easily, measured (and should be measurement-independent), or perhaps more simply calculated through molecular simulations, this could lead to new databases more robust than those presently available for the Flory interaction parameter.

But for now, as Douglas and Bosse put it [27], the Flory-Huggins theory should be considered more like a "phenomenological model" where all the complex physical and chemical phenomena occurring are hidden in the interaction parameter.

Nevertheless, certainly due to its relative simplicity (both theoretical and, to a certain extent, experimental), comparing values of $\chi$ for different polymer couples is still often used to discuss their relative compatibilities (or more often incompatibilities) when blended or to evaluate phase separation in diblock or triblock copolymers. It is relevant to try to analyze what happens at the interfaces in a binary or ternary polymer blend since the physical properties of the blends depend strongly on the morphology. Knowing $\chi$, the phase separation and the resulting properties can then, for example, be analyzed under the framework of the self-consistent field theory initially developed by Helfand [28,29].

In consequence, a measure of this parameter, for a given blend, should still provide useful information. However, this measure remains subject to uncertainties, whether due to the experimental technique itself, the experimental conditions (pressure, temperature or even moisture in some cases [30]) or to the physical and chemical details of the blend composition. The goal of this paper is to show that, for these reasons, comparisons of blends using values of the Flory interaction parameter listed in the literature should be handled with care, and conclusions made with caution.

\section{Experimental techniques to measure $\chi$ for polymer blends or BCP}

In the 50's and later on, some values for polymer blends were obtained from light scattering measurements or osmometry, the second virial coefficient being proportional to $(1-2 \chi)$ [31,32]. More refined measurements were obtained in the 80's also using light scattering experiments based on ternary blends (two polymers within a well-chosen solvent which cancels the polymer-solvent interactions of the two polymers at a given temperature) [33], the authors claiming they are then able to measure the polymer-polymer interactions only.

Another experimental route to obtain this parameter is by using DSC measurements, either by following the heat of mixing [34] (which will not be detailed here) or by studying melting point depressions (for semi-crystalline blends [35]) or $T_{g}$ variations [36]. Concerning this last method, it is possible to determine, by measuring these variations, the composition of the immiscible phases using the Fox and the Couchman equations. Then, one could retrieve the $\chi$ parameter using the following equations derived from the equality of the chemical potentials of each component in both phases:

$$
\chi_{A B}=\frac{\ln \left(\phi_{A}^{\prime \prime} / \phi_{A}^{\prime}\right)+\left(1-m_{A} / m_{B}\right)\left(\phi_{B}^{\prime \prime}-\phi_{B}^{\prime}\right)}{m_{A}\left(\phi_{B}^{\prime 2}-\phi_{B}^{\prime \prime 2}\right)}
$$

And, similarly,

$$
\chi_{A B}=\frac{\ln \left(\phi_{B}^{\prime \prime} / \phi_{B}^{\prime}\right)+\left(1-m_{B} / m_{A}\right)\left(\phi_{A}^{\prime \prime}-\phi_{A}^{\prime}\right)}{m_{B}\left(\phi_{A}^{\prime 2}-\phi_{A}^{\prime \prime 2}\right)}
$$

where $\phi_{A}$ and $\phi_{B}$ are the volume fraction of polymer $\mathrm{A}$ and B, respectively. $m_{i}$ can be correlated to the degree of polymerization, and corresponds to the ratio between the molar volume of one polymer and an arbitrary fictitious volume; $m_{A}$ and $m_{B}$ are related by the following equation:

$$
\frac{m_{A}}{m_{B}}=\frac{\overline{M_{n, A}} / \rho_{A}}{\overline{M_{n, B}} / \rho_{B}}
$$

where $\overline{M_{n, A}}, \overline{M_{n, B}}, \rho_{A}$, and $\rho_{B}$ are the molecular weights and the densities of polymer A and B, respectively.

Eqs. (5) and (6) must give the same calculated value. However, experimental errors may induce slight differences.

The most popular technique to determine $\chi$ has been small-angle neutron scattering since the mid-eighties. It is usually believed to be the most reliable experiment to do so. It can be run either on solutions or melts, or on copolymers above the microphase separation temperature. The scattered intensity is then analyzed using mean-field expressions (usually random phase approximation, RPA, adapted from de Gennes' work on polymer solutions by Leibler for polymer blends and copolymer melts [37,38], or self-consistent field theory from Helfand and Edwards [39,40]). According to Leibler [38], the scattering intensity from a phase-mixed, monodisperse copolymer and assuming incompressibility (which may be strong hypotheses when compared with real blends, as it has been discussed in the theoretical section), is directly related to $\chi$ when knowing the molar volume, density, Kuhn length and the number of Kuhn monomers of each block. Shortly after that, experiments were conducted based on this theoretical work to estimate $\chi$ for various blends or block copolymers [41,42]. Similar experiments (and analyses) were performed using SAXS instead of SANS on non-deuterated copolymers [43]. It has been noted by Sanchez [44] that the $\chi$ obtained here is actually coming from the second derivative of the free energy and is equal to the one presented in Eq. (1) only if there is no blend composition dependence on $\chi$. This composition dependence on $\chi$, though not apparent in the Flory-Huggins theory, has often been observed experimentally and is still the subject of many debates we will not discuss in details in this article (see for example Ref. [45]). It is worth noting that values obtained by SANS are often smaller than those measured by other techniques. 
Another way of using SANS is to measure directly the interphase which is then linked to the Flory interaction parameter via the theoretical work of Helfand and coworkers on unsymmetric polymer-polymer interfaces [46]. A simple scaling argument omitting all prefactors is that the enthalpic cost for $m$ monomers of A penetrating in the B melt is $m \chi k_{B} T$. This cost is on the order of the thermal energy $k_{B} T$ so $m \sim 1 / \chi$. The size interphase (i.e., the region where the chains of both polymers are interpenetrated) $w$ is then $w \sim b m^{1 / 2} \sim b / \chi^{1 / 2}$ with $b$ the Kuhn length of the polymer, assuming a random coil conformation for the polymer chains [47]. A more refined calculation based on Gaussian random walk statistics by Helfand leads for the interphase of an A-B blend to:

$$
\left.w=2 \frac{1}{12 \chi \sqrt{\rho_{0, A} \rho_{0, B}}}\left(\rho_{0, A} b_{A}^{2}+\rho_{0, B} b_{B}^{2}\right)\right)^{1 / 2}
$$

where $\rho_{0}$ is the density of the pure polymer (typically $10^{-2}$ times Avogadro's number monomer units/cm ${ }^{3}$ ) and $b_{A}$ and $b_{B}$ the Kuhn length of polymer $A$ and $B$, respectively.

Assuming the density of the pure polymers are equals, this can be simplified in Eq. ( 8 bis).

$$
w \approx 2\left(\frac{1}{12 \chi}\left(b_{A}^{2}+b_{B}^{2}\right)\right)^{1 / 2}
$$

And if the Kuhn monomers of the two species are similar, Eq. ( 8 bis) can be simplified in Eq. ( 8 ter), which is usually chosen for the analyses (and which is fairly close to the equation obtained via scaling arguments). This simplified equation can be found in Helfand's first paper on the theory of the interface between immiscible polymers [9].

$$
w \approx \frac{2 b}{\sqrt{6 \chi}}
$$

The impact of the molar masses of both polymers on the size of the interphase has been studied by Broseta [48]. If the molar masses are reasonably close and assuming the two polymers have the same Kuhn length $b$, one can write:

$$
w \approx \frac{2 b}{\sqrt{6 \chi}}\left(1+\frac{\ln 2}{\chi}\left(\frac{1}{N_{A}}+\frac{1}{N_{B}}\right)\right)
$$

$N_{A}$ and $N_{B}$ being the number of Kuhn monomers of polymers A and B, respectively.

Also in the 80's, an alternative route has been proposed based on the study of the critical molecular weights at which a polymer pair becomes miscible (cloud points) [49]. Looking at Eq. (1), it is obvious that decreasing the molecular weight will lead to more favorable entropy of mixing which can, at some point, overcome the usually unfavorable energy of mixing. Then, by studying the phase separation as a function of the temperature (for UCST or LCST blends), one can get access to the interaction energy and the interaction parameter. Finally, an indirect method relying on interfacial measurements can be used, using the relation described by Helfand between interfacial tension $\gamma$ and Flory interaction parameter $\gamma=\frac{k T}{b^{2}}\left(\frac{\chi}{6}\right)^{1 / 2}[28,29]$. Several methods for measuring interfacial tension between polymer melts have been proposed in the literature [50].

\section{Calculated values of $\chi$}

Because these experiments are all quite complicated, it is often useful to estimate the interaction parameter using the semi-empirical approach developed for liquids by Hildebrand and Scott [51]. It is based on the solubility parameter $\delta$, which is related to the cohesive energy density CED: $\delta^{2}=$ CED. Since CED is the internal energy (per unit volume), it may be viewed as the amount of energy needed to separate to infinite distance the molecules of a given liquid, hence it corresponds to the energy of vaporization (which is the latent heat of vaporization minus $R T$ where $R$ is the universal gas constant $=8.314 \mathrm{~J} / \mathrm{mol} /$ $\mathrm{K})$. For a molecule $\mathrm{A}$, it is then proportional to $u_{A A}[15]$.

According to this approach, $\chi$ can be approximated for a blend of A and B using the equation:

$$
\chi \approx \frac{v_{A B}}{R T}\left(\delta_{A}-\delta_{B}\right)^{2}
$$

where $v_{A B}$ is the geometric mean of molar volumes of polymer $\mathrm{A}$ and polymer $\mathrm{B}$, which can be estimated using data from Fedor on the molar volumes of constitutive groups [52] and $\left(\delta_{A}-\delta_{B}\right)^{2}$ is the cohesive energy density in $\mathrm{J} / \mathrm{cm}^{3}$.

Solubility parameters have been in use for over 50 years, notably in the coating industry to facilitate solvent selection. This approach based on the principle "like dissolves like" works reasonably well for systems with non-polar interactions but usually offers a poor prediction for systems involving polar interactions or hydrogen bonds because of the assumptions made by Hildebrand (which are that the energy is estimated as the sum of the molecular pair interactions, the molecules are randomly placed in the system and the mixing happens at constant volume, similar to hypotheses made in the Flory-Huggins theory). To study more polar systems, the solubility parameter can be decomposed in polar, non-polar and hydrogen bonds components (respectively $\delta_{P}, \delta_{N P}$ and $\delta_{H}$ with $\delta=\sqrt{\delta_{P}^{2}+\delta_{N P}^{2}+\delta_{H}^{2}}$ ) as introduced by Hansen [53]. We can note that some 
authors recommend the use of a Lewis-acid component $\delta_{A}$ and a Lewis-base component $\delta_{B}$ to replace the hydrogen bonding component $[54,55]$ but the lack of databases for these parameters made them difficult to use in practice. For polymers, the Hansen solubility parameters can be obtained following a complicated set of experiments since it is almost impossible to measure directly their heat of vaporization: the solvation of a given polymer is tested in a variety of solvents with known solubility parameters through series of "trials and errors", with the non-polar component chosen equal to the solubility parameter of an homomorph, i.e. an hydrocarbon component of similar structure. It also involves the use of physical constants such as dipole moment, refractive index, dielectric constant [53], that may not be easily available in the literature. The testing method concerning solvation but also differences in interactions between solvent and polymer may lead to significantly different results and explain why, for many polymers, more than one set of values for polar, non-polar and hydrogen bonds solubility parameters, is available in the literature.

Solubility parameters can also be estimated via empirical group contributions methods (each chemical function is being attributed a partial solubility parameter contributing to the solubility parameter of a given molecule) developed for example by van Krevelen [52] by using the experimental dataset built by Hansen on polymer solutions [53]. This presents the advantage to take into account the molar volume of the constituents, which may play a role in the solubility (smaller solvents may be more effective than bigger molecular species having more favorable solubility parameters). However, as mentioned by Balsara in Ref. [56] (chapter 19, "Thermodynamics of Polymer Blends"), though still in use, group contributions methods usually lead to large errors for polymer blends.

It should also be noted that the values for the solubility parameters are usually given at ambient temperature. To determine their variations with pressure and temperature, empirical equations were proposed by Hansen [53] but more refined numerical methods were also proposed more recently. Utracki [57] developed a method based on thermodynamics statistics using the Simha-Somcynsky model [58] which introduces vacancies in the lattice to take into account free volume in the melt state. This theory gives a direct expression for the cohesive energy density, and thus $\delta$, as a function of the pressure and temperature.

As stated by Utracki [57], the use of solubility parameters for studying polymer blends has had less success than for polymer solutions. Roughly, this may be explained by the fact that one polymer will cause the other to interact with itself in the blend differently than it would in the pure state (thus there might be a "complementarity matching" effect besides the "similarity matching" discussed above). A recent numerical attempt has been made to take into account these effects $[59,60]$ but only a few polymers and polymer mixtures were studied to date and systematic comparison with available data from the literature is still needed to evaluate its potential.

To conclude this section, it should be reminded that, as showed for example in Eqs. (4) and (10), the Flory interaction parameter depends on the temperature, and, as being said earlier, on many factors such as composition, chain length and volume changes or local packing effects not taken into account in the simple lattice model. To better take into account all these factors and capture experimental measurements which often display an important temperature-independent contribution, an empirical relation for the Flory interaction parameter is often used:

$$
\chi(T) \cong A+\frac{B}{T}
$$

with $A$ the temperature-independent additive constant (often called entropic) and $B$ the temperature-dependent constant (often called enthalpic) and expressed in Kelvin (K).

\section{Determination of $\chi_{P S-P M M A}$}

\subsection{Experimental determination}

Let us now move to a widely studied polymer blend, polystyrene (PS) and poly(methyl methacrylate) (PMMA). We will discuss here the discrepancy within measured values for different measurement methods, but also focus specifically on the discrepancies between data obtained by small-angle scattering experiments. We will then compare experimental and calculated values (whether analytically or numerically using solubility parameters).

The first report made by Stockmayer for $\chi_{\text {PS-PMMA }}$ by studying a blend of PS and PMMA of similar molar masses $\left(M_{w} \approx 135,000 \mathrm{~g} / \mathrm{mol}\right)$ in butanone at $25^{\circ} \mathrm{C}$ gives $\chi_{P S-P M M A}=0.014 \pm 0.01$. Using a study on phase separation in ternary blends (PS and PMMA in benzene at room temperature) [61] and an analytical method proposed by Scott [62], they were able to obtain another value for $\chi_{\text {PS-PMMA }}, \chi_{P S-P M M A}=0.011 \pm 0.004$. This value was used by Helfand to estimate the interphase [46] for PS/PMMA blends and he obtained $160 \AA \AA$, much higher than what has been measured directly (see discussion below).

Using the same method but choosing what he claimed was a more appropriate solvent to cancel out polymer-solvent interactions, Fukuda studied PS and PMMA in bromobenzene at $30^{\circ} \mathrm{C}$ and obtained $\chi_{P S-P M M A}=0.025 \pm 0.005$ [33].

In 1990, Russell [63] studied via SANS a PS-b-PMMA diblock copolymer $\left(M_{w}=29,000 \mathrm{~g} / \mathrm{mol}\right)$ with a deuterated PS block (dPS, $M_{w} \approx 13,000 \mathrm{~g} / \mathrm{mol}$ ) at 3 temperatures: $120^{\circ} \mathrm{C}, 162{ }^{\circ} \mathrm{C}$ and $180^{\circ} \mathrm{C}$. $\chi_{P S-P M M A}$ was obtained using Leibler's theoretical work to fit the SANS profiles (it is however worth noting that the equation concerning the interphase as proposed by Helfand used in Ref. [63] is not correct, not being homogeneous to a length - see Eqs. (8) and (9) in the present article). Using values from the literature for the Kuhn lengths of PS and PMMA and finding these values for both polymers are fairly close 
$(\sim 7 \AA)$ they obtained, $\chi_{P S-P M M A}$ at the three temperatures, $\chi_{P S-P M M A}=0.0383$ at $120^{\circ} \mathrm{C}, 0.0373$ at $162{ }^{\circ} \mathrm{C}$ and 0.037 at $180{ }^{\circ} \mathrm{C}$. They claim that, knowing $b_{\mathrm{PS}}$ and $b_{P M M A}$, a $3 \%$ difference in $\chi$ is enough to produce unacceptable fits of the scattering profiles. With these three data points, they then deduced $A$ and $B$ from Eq. (11), $A=0.028 \pm 0.002$ and $B=3.9 \pm 0.6$. These values are often chosen as references in later articles studying PS/PMMA systems (this article has been cited more than 300 times). Assuming this linear relation extends to temperatures as low as room temperature, this equation gives a Flory interaction parameter of 0.041 at $25^{\circ} \mathrm{C}, 4$ times higher than the values previously measured by Stockmayer, and close to twice higher than the ones obtained by Fukuda.

In a later article [64], other blocks of similar molar masses were studied but with the PMMA or both blocks deuterated and at several temperatures between 120 and $200{ }^{\circ} \mathrm{C}$. For the PS-b-PMMA with deuterated PMMA, values of $A=0.0292$ and $B=3.188$ were obtained. For the PS-b-PMMA with both blocks deuterated, Russell obtained $A=0.0251$ and $B=3.199$. Using data for interaction energies obtained by the critical molecular weight method on PS/PMMA blends by Callaghan and Paul [49] (which will be discussed below), he obtained estimated values of $A=0.021$ and $B=3.2$ for homopolymer blends. To do so, Russell used a linear fit for three data points, one by Callaghan, another one from Massa (coming from a private communication), the last being from Fukuda [33]. These results indicate that the deuterium label affects slightly (and, differently, depending on which block is labeled) the measured value of $\chi$ [65]. The effect of deuteration (which might be important in some cases) on the physical properties of blends has been investigated recently [66]. It has also been noted by Bates that SANS values for $\chi$ might differ significantly when obtained on blends and on copolymers [67].

Same analyses were conducted on SAXS experiments by Stühn [43]. The non-deuterated PS-b-PMMA used had $M_{n}=13,300 \mathrm{~g} / \mathrm{mol}$ with a fraction of PS $=0.49$ and was studied at ten temperatures between $120^{\circ} \mathrm{C}$ and $210^{\circ} \mathrm{C}$. The experimental values were fitted using Eq. (11) and the fitting parameters $A$ and $B$ obtained were $\chi=0.035+8.8 / T$. These values are quite higher than those obtained by Russell (for example, $\chi \simeq 0.057$ at $120^{\circ} \mathrm{C}$ for Stühn compared to 0.038 for Russell).

In a more recent paper studying mainly the order-disorder transition in PS-b-PMMA, Zhao et al. [68] also measured $\chi$ at different temperatures with this technique and compared their results to those of Stühn, Russell and Callaghan. Two non-deuterated blocks were studied, quite similar in composition $\left(M_{n}=28,000 \mathrm{~g} / \mathrm{mol}\right.$, volume fraction of PS $=0.56$; $M_{n}=25,700 \mathrm{~g} / \mathrm{mol}$, volume fraction of PS $=0.53$ ) at six temperatures between 180 and $230{ }^{\circ} \mathrm{C}$. They obtained for their system in the form of Eq. (11): $\chi=0.0282+4.46 / T$, similar to the results of Russell on the dPS-b-PMMA systems [63]. The authors also state that this $1 / T$ dependence is only seen for temperatures higher than $T_{M F}$, defined for block copolymers as the crossover temperature from a mean-field disordered state to the non-mean-field, fluctuation-influenced, disordered state. In their work, this $T_{M F}$ for their block copolymers is estimated around $175^{\circ} \mathrm{C}$. They finally comment on the higher values obtained by Stühn [43], making the hypothesis this is due to lower molar masses for the blocks used by Stühn compared with the other studies.

Coming back to the work of Callaghan [49] on cloud point experiments, interaction energies values (noted $B$ in Callaghan's article) are given in $\mathrm{cal} / \mathrm{cm}^{3} . \chi$ is then equal to $\frac{B v_{0} * 4.184}{R T}$ with $v_{0}$ the molar volume of the blend and 4.184 a numerical factor to convert Joules in calories. Taking a value for $v_{0}$ of $100 \mathrm{~cm}^{3} / \mathrm{mol}$, they obtained two values for $\chi$ at $200{ }^{\circ} \mathrm{C}$, using two different analyses, 0.033 using Flory-Huggins and 0.037 using Sanchez-Lacombe equation of state with a binary interaction model [69] to extrapolate the experimental data [23]. With this experimental analysis, they also point out that PS and PMMA are actually partially miscible if both molar masses are below values on the order of $10 \mathrm{~kg} / \mathrm{mol}$ (or even totally miscible below $3 \mathrm{~kg} / \mathrm{mol}$ ).

In a study by Fernandez [70], where the interphase between PS and PMMA was measured via SANS on a thin $(\sim 20 \mathrm{~nm})$ deuterated PMMA film $\left(M_{w}=19,000 \mathrm{~g} / \mathrm{mol}\right)$ on top of a thicker $(\sim 800 \mathrm{~nm})$ PS substrate $\left(M_{w}=220,000 \mathrm{~g} / \mathrm{mol}\right)$ at $120^{\circ} \mathrm{C}$, a value for $\chi_{P S-P M M A}$ is also given: $\chi_{P S-P M M A}=0.0061$. This surprisingly low value is obtained from the mutual diffusion coefficient $D$ measured in the study, and values for the transport coefficient $D_{T}$ taken from the literature, the two being linked by the relation $D=2\left(\chi_{c}-\chi\right) \phi(1-\phi) D_{T}$. However, this analysis is valid for miscible blends [71], i.e. for $\chi<\chi_{c}$. In their case, $\chi_{c} \sim 0.01$ and since $D$ and $D_{T}$ are necessarily positive, the obtained value for $\chi$ has to be smaller than $\chi_{c}$, which does not make sense in the case of an immiscible blend. Another way to see this is that when this value for $\chi$ is used along with their interphase measurement in Eq. ( 8 ter), this leads to a Kuhn monomer length of $2.4 \AA$ (and even smaller if using Eq. (9)). This is unreasonably small, since it is close to the value of the "real" monomer length (i.e. 2 C - C bonds with a $109^{\circ}$ angle) and does not take into account the local correlations between bond vectors due to restricted bond angles and steric hindrance caused mainly by the lateral groups of the monomers, which are important in the cases of PS and PMMA.

This analysis has also recently been made by Hu et al. [72] in an article where they measured diffusion and tracer mutual coefficients for PS/PMMA via confocal Raman microscopy. This study has been subjected to debate, Tomba [73] arguing on the spatial resolution of the technique which is not, according to him, sufficient to measure polymer diffusion in immiscible blends. Depending on the theoretical analysis performed (slow theory, ST, or fast theory, FT), they report values between -0.033 and -0.013 for the blends between 130 and $150{ }^{\circ} \mathrm{C}$, which also clearly appears unreasonable for PS/PMMA blends.

We can also briefly discuss interfacial tension measurements for PS/PMMA and use it to estimate $\chi$ from the relation proposed by Helfand, $\gamma=\frac{k T}{b^{2}}\left(\frac{\chi}{6}\right)^{1 / 2}$. Wu used a pendant drop apparatus to study several blends at different temperatures (100$200^{\circ} \mathrm{C}$ ) [74]. He obtained for all blends a linear dependence of $\gamma$ with the temperature (probably not valid below $T_{g}$ ), and for PS/PMMA the following relation: $y=3.2-0.013(T-20)$ with $T$ in ${ }^{\circ} \mathrm{C}$ and $y$ in $\mathrm{mJ} / \mathrm{m}^{2}$. With this, we can obtain for example $\chi=0.073$ at $160^{\circ} \mathrm{C}$ and $\chi=0.025$ at $200^{\circ} \mathrm{C}$ with $b \approx 7 \AA$. Another study from Carriere leads to $y=3.6-0.013 T$ in the $160-$ $250{ }^{\circ} \mathrm{C}$ range by the imbedded fiber retraction method [75], giving $\chi=0.0892$ at $160{ }^{\circ} \mathrm{C}$ and $\chi=0.038$ at $200{ }^{\circ} \mathrm{C}$ with $b \approx 7 \AA$. 
Similarly to Broseta's work for the interphase, Tang and Freed [76] developed a model to take into account the role of the molar masses in the interfacial tension for symmetric blends $\left(N_{A}\right.$ and $\left.N_{B}=N\right): \gamma=\frac{k T}{b^{2}}\left(\frac{\chi}{6}\right)^{1 / 2}\left(1-\frac{1.8}{\chi N}-\frac{0.4}{(\chi N)^{2}}\right)^{3 / 2}[2]$. However, in both Carriere and Wu experiments, blends were strongly asymmetric $\left(M_{w P S}>10 M_{w P M M A}\right)$ so this refined model could not be used.

All these data are now summarized in Table 1. In bold are actual experimental values extracted from the mentioned references. In plain text are values calculated at other temperatures (used later on in the article for comparisons with other systems) or when the raw data were not available in the references, using Eq. (11) and $A$ and $B$ as given in the references.

To summarize, it appears that, even for a "simple" system such as PS/PMMA analyzed with the same experimental technique (say, small-angle scattering) and the same theoretical analysis with the same fitting parameter (for example, here, $b \approx 7 \AA$ ), one can get access to experimental values for $\chi_{P S-P M M A}$ showing almost a factor of 2 at a given temperature (for example, from 0.028 to 0.054 at $180{ }^{\circ} \mathrm{C}$ with scattering measurements, with a mean value of 0.038 and a standard deviation of 0.009), depending on the nature of the system studied (block or blend, deuterated or not) and its characteristics (molar masses, volume fraction of the blend/block). This is summarized in Fig. 2, where the averaged values (and the corresponding standard deviations) from all scattering experiments are plotted as a function of $1 / \mathrm{T}$. We can note that new values for $A$ and $B$ can be extracted from this plot, $A_{a v}=0.0276, B_{a v}=4.56$.

The situation is even worse (some results may differ by more than a factor of 5 ) if different experimental techniques are compared, even if one does not consider "anomalous" results such as negative $\chi$ values.

Table 1

Summary of all experimental data for $\chi_{\text {PS-PMMA. }}$

\begin{tabular}{|c|c|c|c|c|c|c|c|c|}
\hline$\chi_{\text {PS-PMMA measured }}$ & $\mathrm{T}=25^{\circ} \mathrm{C}$ & $120^{\circ} \mathrm{C}$ & $162{ }^{\circ} \mathrm{C}$ & $180^{\circ} \mathrm{C}$ & $200^{\circ} \mathrm{C}$ & $250^{\circ} \mathrm{C}$ & A & $\mathrm{B}$ \\
\hline Turbidity [31] & 0.014 & & & & & & & \\
\hline Turbidity [31] & 0.011 & & & & & & & \\
\hline Light scattering [33] & $\begin{array}{l}\mathbf{0 . 0 2 5} \\
\left(30^{\circ} \mathrm{C}\right)\end{array}$ & & & & & & & \\
\hline SANS (dPS-b-PMMA) [63] & 0.041 & 0.0383 & 0.0373 & 0.037 & 0.0362 & 0.0355 & 0.028 & 3.9 \\
\hline SANS (PS-b-dPMMA) [64] & 0.0399 & 0.0373 & 0.0365 & 0.0362 & 0.0359 & 0.0353 & 0.0292 & 3.19 \\
\hline SANS (dPS-b-dPMMA) [64] & 0.0358 & 0.0332 & 0.0325 & 0.0322 & 0.0319 & 0.0312 & 0.0251 & 3.2 \\
\hline Estimated from critical molecular weight method (PS/PMMA blend) $[64,49]^{\mathrm{a}}$ & 0.0317 & 0.0291 & 0.0284 & 0.0281 & 0.0278 & 0.0271 & 0.021 & 3.2 \\
\hline SAXS (PS/PMMA) [43] & 0.0645 & 0.0574 & 0.0552 & 0.0544 & 0.0536 & 0.0518 & 0.035 & 8.8 \\
\hline SAXS (PS/PMMA) [68] & 0.0432 & 0.0395 & 0.0385 & 0.038 & 0.0376 & 0.0367 & 0.0282 & 4.46 \\
\hline Critical molecular weight method (Flory-Huggins) [49] & & & & & 0.028 & & & \\
\hline Critical molecular weight method (Sanchez-Lacombe) [49] & & & & & 0.034 & & & \\
\hline SANS (from diffusion coefficients) [70] & & 0.0061 & & & & & & \\
\hline \multirow[t]{2}{*}{ Confocal Raman microscopy (from diffusion coefficients) [72] } & & $\left(130{ }^{\circ} \mathrm{C}\right)$ & $\left(150{ }^{\circ} \mathrm{C}\right)$ & & & & & \\
\hline & & $\begin{array}{l}-0.0316 \\
(\mathrm{FT}) \text { or } \\
-0.0131 \\
\text { (ST) }\end{array}$ & $\begin{array}{l}-0.0338 \\
(\mathrm{FT}) \text { or } \\
-0.0152 \\
\text { (ST) }\end{array}$ & & & & & \\
\hline From interfacial measurements [74] and Helfand's equation [28,29] & & 0.177 & 0.0733 & 0.0462 & 0.025 & 0.0012 & & \\
\hline From interfacial measurements [75] and Helfand's equation [28,29] & & 0.204 & 0.0892 & 0.0585 & 0.0338 & 0.0034 & & \\
\hline
\end{tabular}

a Obtained by Russell from measurements obtained using different methods and listed in Callaghan's article.

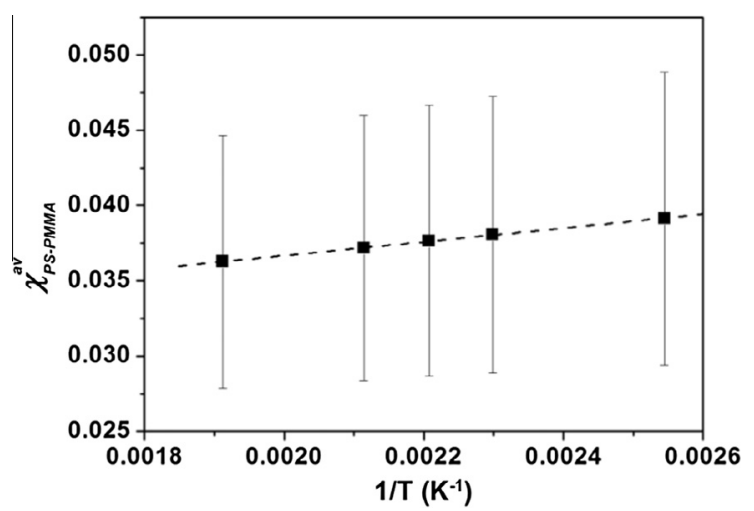

Fig. 2. Averaged values (and standard deviations) for $\chi_{P S-P M M A}$ from all small-angle scattering experiments on PS/PMMA various systems [63,64,43,68]. 
One can now see what happens when considering that some parameters used in the analyses made in the aforementioned studies may also raise uncertainties.

\subsection{Reestimated values from the previous experiments}

Taking the obtained $\chi$ values measured by Russell at $120^{\circ} \mathrm{C}$ and $162^{\circ} \mathrm{C}[63]$ and an average Kuhn monomer length of $7 \AA$ as used by Russell, one can get an estimate of the interphase via Eq. (9). This interphase is $w \approx 52 \AA$ at both temperatures. This is consistent with direct measurements of the interphase in thin films of diblock copolymers PS-b-PMMA with deuterated PMMA also obtained by SANS in Russell's group: $54 \AA \pm 2 \AA$ at $170{ }^{\circ} \mathrm{C}$ [77].

However, we should state that large differences are also observed on the monomers length from PS and PMMA. If the "real" monomer length is about $2.5 \AA$ for every vinyl monomer, the Kuhn length is usually also obtained from scattering measurements. If Russell reports a value of $6.8 \AA$ for PS, extracted from values of radius of gyration measured by Ballard [78] and 7.3 $\AA$ for PMMA measured by SAXS by Kirste [79] (in an article in German), $b=18 \AA$ for PS and in the range 15$17 \AA$ for PMMA can be obtained using the work of Fetters $[15,56,80]$. If we assume the interphase is indeed around $50 \AA$ but use these values for the Kuhn length instead of the one chosen by Russell in Eq. (9), then we obtain a value of about 0.149 for $\chi_{P S-P M M A}$ at $120^{\circ} \mathrm{C}$, about 4 times higher (looking at Eq. (6) ter, one can understand this is roughly the ratio of the two "average" Kuhn lengths - 7 and $17 \AA$ - squared) than what is reported in Ref. [63].

Coming back to Fernandez study, it is possible to use their interphase measurement (20 ̊, fairly smaller than what was obtained by Russell) to obtain $\chi$ with Eq. (9), using either $b$ given by Russell $[63,79]$ or by Fetters $[15,56,80]$. This leads to $\chi_{P S-P M M A}=0.103$ and $\chi_{P S-P M M A}=0.526$ at $120^{\circ} \mathrm{C}$ respectively, way higher than what has previously been estimated. It has been noted by Jones and Randal [2] that the discrepancy between Fernandez and Russell values is due to the function chosen to fit the interfacial width. While Russell used a tanh function, Fernandez chose an error function profile. If one multiplies Fernandez value by $\sqrt{2 \pi}$, one obtains $50 \AA$, then very similar to what Russell reports.

A final reexamination concerns Callaghan's analysis. They took $100 \mathrm{~cm}^{3} / \mathrm{mol}$ for the molar volume of the blend. However, a more precise estimate of the mean molar volume may be obtained from van Krevelen [52]. For PS and PMMA, the mean value $\left(\sqrt{v_{A} \times v_{B}}\right)$ is $92.1 \mathrm{~cm}^{3} / \mathrm{mol}$ (with $v_{P M M A}=86.5 \mathrm{~cm}^{3} / \mathrm{mol} ; v_{P S}=98 \mathrm{~cm}^{3} / \mathrm{mol}$ ). This would then lead to 0.026 and 0.031 respectively for $\chi$ at $200^{\circ} \mathrm{C}$ (the temperature at which they performed their experiments).

Reestimated values for $\chi_{\text {PS-PMMA }}$ using the previously discussed experimental results are then summarized in Table 2 (as a reminder, relevant data from Table 1 used in these comparisons are repeated in Table 2). This shows that the uncertainty concerning fundamental molecular parameters such as the Kuhn monomer length will greatly impact the "measured" value of $\chi$.

\subsection{Calculated values for $\chi_{P S-P M M A}$}

We will now see that this is even worse with calculated values for $\chi_{\text {PS-PMMA. }}$

If we want to estimate the values of $\chi$ by using Eq. (10), we first need an estimate of the mean molar volume, taken as above from van Krevelen [52]. The cohesive energy density is obtained via the solubility parameters found in Ref. [56] or [81]: however, many values for the solubility parameters are listed in the Polymer Handbook, whether calculated or obtained via various experimental techniques. For PS, $\delta$ usually varies from 17.4 to $19.8\left(\mathrm{~J} / \mathrm{cm}^{3}\right)^{0.5}$ (or MPa ${ }^{0.5}$ ) but values as low as 15.1 and as high as 22.47 are reported, while for PMMA, values such as 18.6, 18.9, 19.4 or 26.27 can be found. So, one has to be conscious that, by taking reported values for solubility parameters and using Eq. (9), the Flory interaction parameter can vary by an extremely large amount: in the case of PS/PMMA at room temperature for example, from 0 to 4.6 (!) if one takes the extreme values that can be obtained.

One has then to be careful, not only to select data from the Handbook, but probably also to choose data taken from the same reference measured or calculated using the same method. In Ref. [81], there are several values for $\delta_{P S}$ and $\delta_{P M M A}$ coming

Table 2

Comparison of experimental and recalculated data for $\chi_{P S-P M M A}$.

\begin{tabular}{|c|c|c|c|c|}
\hline$\chi_{P S-P M M A}$ & $120{ }^{\circ} \mathrm{C}$ & $162{ }^{\circ} \mathrm{C}$ & $180^{\circ} \mathrm{C}$ & $200{ }^{\circ} \mathrm{C}$ \\
\hline \multicolumn{5}{|l|}{ Measured } \\
\hline SANS (dPS-b-PMMA) [63] & 0.0383 & 0.0373 & 0.037 & 0.0362 \\
\hline Critical molecular weight method (Flory-Huggins) [64] with $v_{0}=100 \mathrm{~cm}^{3} / \mathrm{mol}$ & & & & 0.028 \\
\hline Critical molecular weight method (Sanchez-Lacombe) [64] with $v_{0}=100 \mathrm{~cm}^{3} / \mathrm{mol}$ & & & & 0.034 \\
\hline \multicolumn{5}{|l|}{ Reestimated } \\
\hline Recalculated from [63] with Eq. (9) and b $\approx 17 \AA$ (Fetters) [80] & 0.149 & 0.146 & 0.145 & 0.141 \\
\hline Flory-Huggins with $v_{0}=92.1 \mathrm{~cm}^{3} / \mathrm{mol}$ (from van Krevelen) [52] & & & & 0.026 \\
\hline Sanchez-Lacombe with $v_{0}=92.1 \mathrm{~cm}^{3} / \mathrm{mol}$ (from van Krevelen) [52] & & & & 0.031 \\
\hline Recalculated from Fernandez [70] with Eq. (9) and Kirste values for $b$ [79] & 0.103 & & & \\
\hline Recalculated from Fernandez [70] with Eq. (9) and Fetters values [80] & 0.526 & & & \\
\hline
\end{tabular}


Table 3

Summary of the calculated values for $\chi_{\text {PS-PMMA }}$ using solubility parameters.

\begin{tabular}{|c|c|c|c|c|c|c|c|c|}
\hline$\chi_{P S-P M M A}$ & $25^{\circ} \mathrm{C}$ & $120^{\circ} \mathrm{C}$ & $162{ }^{\circ} \mathrm{C}$ & $180^{\circ} \mathrm{C}$ & $200^{\circ} \mathrm{C}$ & $250^{\circ} \mathrm{C}$ & A & $\mathrm{B}$ \\
\hline \multicolumn{9}{|c|}{$\begin{array}{l}\text { Calculated using Eq. (10) (assuming constant values for } \delta \text { with } T \\
\text { except for data from Utracki) [57] }\end{array}$} \\
\hline$\delta_{P S}=17.52$ and $\delta_{P M M A}=18.58$ from Ref. $[82]^{\mathrm{a}}$ & 0.0418 & 0.0317 & 0.0286 & 0.0275 & 0.0263 & 0.024 & 0 & 12.45 \\
\hline$\delta_{P S}=22.47$ and $\delta_{P M M A}=22.69$ from Hansen $[53,83]^{\mathrm{b}}$ & 0.0018 & 0.00136 & 0.00123 & 0.00118 & 0.00113 & 0.00104 & 0 & 0.536 \\
\hline$\delta_{P S}=19.09$ and $\delta_{P M M A}=26.27^{c}$ & 1.916 & 1.453 & 1.313 & 1.261 & 1.207 & 1.102 & 0 & 571.1 \\
\hline$\delta_{P S}=17.5$ and $\delta_{P M M A}=18.58^{\mathrm{d}}$ & 0.0433 & 0.0329 & 0.0297 & 0.0285 & 0.0273 & 0.0249 & 0 & 12.9 \\
\hline$\delta_{P S}=19.26$ and $\delta_{P M M A}=21.52($ exp. [84]) [53] & 0.1899 & 0.1440 & 0.1301 & 0.1249 & 0.1196 & 0.109 & 0 & 56.6 \\
\hline$\delta_{P S}=19.26$ and $\delta_{P M M A}=22.35$ (calc.) $[53]$ & 0.3549 & 0.2691 & 0.2432 & 0.2335 & 0.2236 & 0.2042 & 0 & 105.8 \\
\hline Using $\delta_{P S}$ and $\delta_{P M M A}$ from Ref. [57] & 0.249 & $0.162^{\mathrm{e}}$ & $0.137^{e}$ & $0.128^{\mathrm{e}}$ & $0.0118^{\mathrm{e}}$ & $0.097^{e}$ & -0.099 & 102.7 \\
\hline
\end{tabular}

${ }^{\text {a }}$ Values obtained from viscosity measurements in various solvents at $25^{\circ} \mathrm{C}$.

b Values calculated at $25^{\circ} \mathrm{C}$ from molar-attraction constants of constitutive chemical groups.

c Taken directly from Grulke in Ref. [81]. It is stated they come from "Schwartz, Kolloidnyi Zhurnal, 1956, 18, 755" which could not be found in the archives of the journal. The only other information given by Grulke is that these values were obtained at $25{ }^{\circ} \mathrm{C}$.

${ }^{\mathrm{d}}$ From Grulke [81], extracted from Tobolsky, "Properties and structure of polymers", Wiley, New-York, 1960 (p. 64-66); this book could not be obtained by the authors.

e Calculated with $\chi=A+B / T$, with A and B determined using Utracki's data at ambient temperature, $100-105{ }^{\circ} \mathrm{C}\left(\mathrm{making}\right.$ the hypothesis that the $T_{\mathrm{g}} \mathrm{S}$ are equal for PS and PMMA), $300^{\circ} \mathrm{C}$ and $400-405^{\circ} \mathrm{C}$.

from the same references. Just studying these sets of data leads to cohesive energy density still ranging from 0.04 to $52 \mathrm{~J} / \mathrm{cm}^{3}$ (!). At room temperature, this leads to $\chi_{P S-P M M A}=0.00149, \chi_{P S-P M M A}=0.0018, \chi_{P S-P M M A}=0.0027, \chi_{P S-P M M A}=0.042$, $\chi_{P S-P M M A}=0.061$ and $\chi_{P S-P M M A}=1.92$.

Another possible problem with this approach is that one usually assumes $\delta$ is a constant while it should depend on the temperature [53]. However, most of the experimental values are obtained at room temperature, so using Eq. (10) to determine $\chi$ at high temperature might also create misinterpretations.

Less scattered data have been compiled in a more recent paper by Utracki [57], taking into account the influence of the temperature on the solubility parameter. Several computed values at different temperatures were reported. At room temperature, the average value reported for $\delta_{P S}$ is 22.69 and 25.28 for $\delta_{P M M A}$, leading to $\chi_{P S-P M M A}=0.249$. In his work, Utracki gives values at three other temperatures: $300 \mathrm{~K}, T_{g}$ and $T_{g}+300 \mathrm{~K}$. These values are also compared to typical ones extracted from Grulke usually valid at room temperature [81] (however, it can be noted that for PMMA for example, the value listed by Utracki cannot be found in Ref. [81]). Since PS and PMMA have close $T_{g} s$ ( $373 \mathrm{~K}$ and $378 \mathrm{~K}$, respectively, in Utracki's paper) and since the change in $\delta$ over a few degrees is small, these values can be used together to determine $\chi$ at four temperatures and, consequently, $A$ and $B$ from Eq. (10).

This leads to a new expression for $\chi_{P S-P M M A}, \chi_{P S-P M M A}=-0.0989+102.68 / T$, very different from the one determined by Russell. At $180^{\circ} \mathrm{C}$, this equation yields $\chi_{P S-P M M A}=0.128$, again much higher than results obtained by Russell but closer to those recalculated with Fetters values for $b$.

All these data are compiled in Table 3.

By looking at Table 3, one has to agree with Balsara [56] who states that such approach will lead to large errors for polymer blends, making this method useless when trying to compare different polymers or blends in terms of miscibility. So, despite its simplicity and the fact that many authors still refer to it, we believe it would be better if avoided completely.

\section{Determination of $\chi_{P C-P M M A}$}

By looking at the Flory interaction parameter for another polymer pair, namely PC and PMMA, less data are compiled in the literature, comparatively to the PS/PMMA couple. Kim et al. [36] have been looking at the parameter for this couple by using DSC measurements and especially by measuring $T_{g}$ variations as described above.

Two calculated $\chi$ were obtained using Eqs. (5) and (6) and averaged to minimize the experimental errors. In two separated papers, and through this technique, they calculated a value from two PC/PMMA blends, one made by extrusion at $250{ }^{\circ} \mathrm{C}(\chi=0.039 \pm 0.004[36,85])$ and the other from solvent casting at $25^{\circ} \mathrm{C}(\chi=0.043 \pm 0.004$ [36,85]). Similarly, Kolarik et al. determined this parameter via DSC and DMTA measurements and obtained a value of $0.035 \pm 0.010$ [86].

Callaghan and Paul [87] also studied this blend by the critical molecular weight method which leads to an interaction

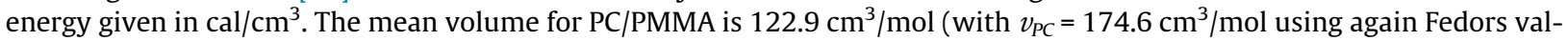
ues from van Krevelen) [52]. The experimental value obtained at $50{ }^{\circ} \mathrm{C}$ is then $\chi \approx 0.012$. What they also claim is that Kim and Burns should use the weight average molecular weight and not the number average molecular weight in Eqs. (5) and (6). In that case, Kim and Burns values at $25^{\circ} \mathrm{C}$ and $250{ }^{\circ} \mathrm{C}$ should be 0.0186 and 0.0169 respectively (the polydispersity index in Kim study being 2.3) [88].

Carriere studied the interfacial tension for PC/PMMA blends [89] and found $1.44 \mathrm{~mJ} / \mathrm{m}^{2}$ at a temperature of $240{ }^{\circ} \mathrm{C}$. PC has a smaller Kuhn length than PS and PMMA. Using data from Wu [90] on the characteristic ratio, one can estimate $b_{P C} \approx 5 \AA$. Assuming densities are equals and using Helfand's model [40], two very different values can be obtained for $\chi$, depending on the Kuhn length chosen for PMMA, $7.3 \AA$ [79] or $15 \AA$ [80]. In the first case, $\chi \approx 0.0355$, while in the second one $\chi \approx 0.248$ which seems unreasonably high. 
Summary of all data for $\chi_{P C-P M M A}$.

\begin{tabular}{|c|c|c|c|c|c|}
\hline$\chi_{P C-P M M A}$ & $25^{\circ} \mathrm{C}$ & $50{ }^{\circ} \mathrm{C}$ & $250^{\circ} \mathrm{C}$ & A & $\mathrm{B}$ \\
\hline \multicolumn{6}{|l|}{ Measured } \\
\hline DSC ( $T_{g}$ S measurements, solvent cast at $25^{\circ} \mathrm{C}$ and extruded blend at $250^{\circ} \mathrm{C}$ ) $[36,85]$ & 0.043 & $0.0423^{\mathrm{a}}$ & 0.039 & 0.0337 & 2.77 \\
\hline DSC measurements [36] recalculated by Callaghan [87] & 0.0186 & & 0.0169 & & \\
\hline Critical molecular weight method with $v_{0}=122.9 \mathrm{~cm}^{3} / \mathrm{mol}$ [87] & & 0.012 & & & \\
\hline Critical molecular weight method with $v_{0}=212.4 \mathrm{~cm}^{3} / \mathrm{mol}[87]$ & & 0.02 & & & \\
\hline DSC ( $T_{g}$ s of extruded blends) [86] & & & 0.035 & & \\
\hline From interfacial tension measurements [89] with $b$ from $\mathrm{Wu}[90]$ and Kirste [79] & & & 0.0355 (at $240^{\circ} \mathrm{C}$ ) & & \\
\hline From interfacial tension measurements [89] with $b$ from Wu [90] and Fetters [80] & & & 0.248 & & \\
\hline \multicolumn{6}{|l|}{ Calculated } \\
\hline Using $\delta_{P C}$ and $\delta_{P M M A}$ from Ref. [57] & 0.032 & $0.029^{\mathrm{b}}$ & $0.018^{\mathrm{b}}$ & 0 & 9.41 \\
\hline$\delta_{P C}=19.7$ and $\delta_{P M M A}=19.98[57]^{\mathrm{C}}$ & 0.0039 & 0.0036 & 0.0022 & 0 & 1.16 \\
\hline$\delta_{P C}=20.25$ and $\delta_{P M M A}=21.52$ (exp.) $[53]$ & 0.0800 & 0.0738 & 0.0456 & 0 & 23.84 \\
\hline$\delta_{P C}=20.43$ and $\delta_{P M M A}=22.35$ (calc.) $[53]$ & 0.1829 & 0.1687 & 0.1042 & 0 & 54.49 \\
\hline
\end{tabular}

a Calculated with $\chi=A+B / T$, with $A$ and $B$ determined using Kim's data at ambient temperature and $250{ }^{\circ} \mathrm{C}$ (only two data points being available to obtain two parameters...).

${ }^{b}$ Calculated with $\chi=A+B / T$, with $A$ and $B$ determined using Utracki's data at ambient temperature and $300{ }^{\circ} \mathrm{C}$ (not shown here). In that case, the approximation that the $T_{g} s$ are identical could not be made, contrary to the PS/PMMA case. Thus, $A$ and $B$ were again here determined using only two data points $\left(25^{\circ} \mathrm{C}\right.$ and $300{ }^{\circ} \mathrm{C}$ ).

' In Utracki's article, these values are given and it is said they come from Grulke [81]. However, the solubility parameter for the PC could not be found by the authors of the present article in Ref. [81].

As for the calculated $\chi$, we used Eq. (10) to interpolate the values at different temperatures. Likewise, this pair is similar to the previous one, in the sense that more than two decades can separate interaction parameters for PC/PMMA blends calculated with solubility parameters chosen from a same reference.

The results are compiled in Table 4 below.

Similar to the PS/PMMA case, results obtained from different measurements may differ substantially (from 0.01 to 0.04 at $50{ }^{\circ} \mathrm{C}$ for example). The analysis of the results may also strongly impact the obtained results (from 0.0169 to 0.039 at $250{ }^{\circ} \mathrm{C}$ as pointed out by Callaghan) [87]. Again, the calculated values differ by more than a decade depending on the reference chosen for the solubility parameters. Scattering measurements have not been performed on this blend, to the best of our knowledge.

\section{Determination of $\chi_{P C-P S}$}

Kim et al. also studied through the aforementioned technique the interaction parameter between PS $\left(M_{n}=98,600 \mathrm{~g} / \mathrm{mol}\right.$, $\mathrm{PDI}=2.41)$ and PC $\left(M_{n}=12,300 \mathrm{~g} / \mathrm{mol}, \mathrm{PDI}=2.36\right)$. They obtained 0.041 and 0.051 for blends made from extrusion at $250^{\circ} \mathrm{C}$ and solution casting, respectively [85]. In a previous paper [91], they also measured $0.038 \pm 0.004$ for extruded blends at $250{ }^{\circ} \mathrm{C}$. Callaghan, in Ref. [87] also gives interaction energies (in $\mathrm{cal} / \mathrm{cm}^{3}$ ) for PS/PC, which can be converted in $\chi$ knowing the molar volume and the temperature. Here, a mean molar volume of $130.8 \mathrm{~cm}^{3} / \mathrm{mol}$ was taken using the same molar volume as previously for the pure components.

The results, including calculated values, are summarized in Table 5 below.

The conclusions are again similar with the few experimental data available in the literature.

Table 5

Summary of all data for $\chi_{P C-P S}$.

\begin{tabular}{|c|c|c|c|c|c|}
\hline$\chi_{P C-P S}$ & $\mathrm{~T}=25^{\circ} \mathrm{C}$ & $\mathrm{T}=50^{\circ} \mathrm{C}$ & $\mathrm{T}=250^{\circ} \mathrm{C}$ & A & $\mathrm{B}$ \\
\hline \multicolumn{6}{|l|}{ Measured } \\
\hline DSC ( $T_{g} \mathrm{~S}$ of extruded blend) [91] & & & 0.038 & & \\
\hline DSC ( $T_{g} \mathrm{~S}$ of solution cast blend) [85] & 0.051 & & & & \\
\hline DSC ( $T_{g} \mathrm{~S}$ of extruded blend) [85] & & & 0.041 & & \\
\hline Critical molecular weight (Flory Huggins) [87] & $0.096^{\mathrm{a}}$ & 0.0876 & $0.05^{\mathrm{a}}$ & & \\
\hline Critical molecular weight (Sanchez Lacombe) [87] & & 0.0897 & & & \\
\hline \multicolumn{6}{|l|}{ Calculated } \\
\hline Using $\delta_{P C}$ and $\delta_{P S}$ from Ref. [57] & 0.607 & & $0.346^{\mathrm{b}}$ & 0 & 180.8 \\
\hline$\delta_{P C}=19.7$ and $\delta_{P S}=18.7$ from Ref. $[57]^{\mathrm{C}}$ & 0.0528 & & 0.0301 & 0 & 15.73 \\
\hline$\delta_{P C}=20.25$ and $\delta_{P S}=19.26$ (exp.) [53] & 0.0517 & & 0.0295 & 0 & 15.42 \\
\hline$\delta_{P C}=20.43$ and $\delta_{P S}=19.26$ (calc.) [53] & 0.1829 & & 0.0412 & 0 & 21.54 \\
\hline
\end{tabular}

\footnotetext{
${ }^{a}$ Extrapolated value.

b Calculated with $\chi=A+B / T$, with the same remark as for the PC/PMMA blend.

c Utracki citing Grulke, same remark as previously for the PC solubility parameter.
} 


\section{Conclusions}

To conclude, let us now try to compare PS/PMMA, PC/PMMA and PC/PS in terms of Flory interaction parameters. First, it is noteworthy that even for these three "simple" blends, no values obtained using the same experimental technique can be found in the literature. As discussed previously, this makes comparisons between the Flory parameter of the three blends even more difficult.

For example at $250^{\circ} \mathrm{C}$, experimental values (or extrapolated ones from experiments), whatever the experimental technique chosen for PS/PMMA, range in between 0.0271 and 0.0518. For PC/PMMA, $\chi$ lies in between 0.017 and 0.039 . For PC/PS, $\chi$ lies in between 0.038 and 0.05 .

This does not take into account the large possible uncertainty in the analysis of the experimental data (whether on the Kuhn length value, on the molar masses of the samples, on the molar volume of the blend, etc.) for PS and PMMA which would have a great impact on these values, as discussed above.

It appears all these values lie within the same range and uncertainties are probably too large for more refined comments. PC/PMMA may well be the most favorable blend when comparing $\chi$ which could be what one would guess when comparing chemical structures, while it would be reasonable to assume PS/PMMA should be the blend with the worst "compatibility". "Compatibility" of the PC/PMMA blend has indeed been discussed in the literature, and this blend appears to display a LCST behavior leading to a miscibility window $[92,93]$. But these different behaviors are hard to predict by looking at $\chi$ values only, as Tambasco [12] pointed out for other systems.

Values using solubility parameters range in between 0.001 and 1.1 (!) for PS/PMMA, 0.002 and 0.1 for PC/PMMA and 0.03 and 0.35 for PC/PS. From this, it clearly appears that nothing can be said for a given blend, let alone when comparing different blends and discuss compatibility or interphase [94,95], unless one knows beforehand what data must be chosen to support their conclusion.

From this, we can conclude that:

1. As already stated by others, though $\chi$ should be a constant according to the simple mean-field lattice model of FloryHuggins, it actually depends in a complex way on many parameters such as temperature, composition of the blend (or of the copolymer), molar masses, tacticity, chemical modification of the polymers (deuteration), whether it has been measured on block copolymers or blends, and even to some extent on the experimental technique chosen to measure it (depending on if it probes the free energy itself, its first or its second derivative) [44].

2. In view of currently available data, one should avoid using solubility parameters to estimate $\chi$ for polymer blends, even more when comparing different blends, and even if solubility parameters are coming from the same set of experimental data or numerical analyses.

3. One should only deal with experimental values but still be careful with what are sometimes considered as absolute values for $\chi$ : as pointed out, many fitting parameters used to obtain these values are also complicated to measure ( $b$ for example) leading to significantly different data in the literature, which will in turn affect the "measured" value obtained for $\chi$. In other words, all the experimental techniques and related analyses to obtain $\chi$ give rise to (potentially large) uncertainties.

4. If possible, one should compare experimental results obtained with the same experimental technique (and with analyses made using the same assumptions), as there may be several $\chi$ substantially different from each other [44]. Unfortunately, since experimental techniques to obtain $\chi$ are never straightforward, only a few experimental data are available for a very small number of "model" blends (such as PS/PMMA). Moreover, due to the numbers of experimental techniques available, it is almost impossible to find $\chi$ values for different systems obtained using the same experimental technique.

5. Even for a given experimental method, a given theoretical analysis and given parameters, values for $\chi$ are obtained with an accuracy no better than $\pm 25 \%$ (as showed with results obtained by different groups using small-angle scattering experiments on PS/PMMA).

All that being said, it is then in any case probably unreasonable to conclude anything about comparison of nanoscale compatibility (for example, the size of the interphase) between two different blends or BCPs if there is less than a factor of 2 difference in their respective measured $\chi$.

\section{Acknowledgement}

The authors would like to thank F. Restagno for careful reading of the manuscript and helpful comments. The authors are grateful to both anonymous reviewers, for pointing out many interesting references. The authors also believe the manuscript strongly benefited from their insightful comments and suggestions.

\section{References}

[1] L.A. Utracki, Polymer Blends Handbook, Springer, Netherlands, 2003.

[2] R.A.L. Jones, W.R. Randal, Polymers at Surfaces and Interfaces, Cambridge University Press, 1999.

[3] W. Soontaranum, J.S. Higgins, T.D. Papathanasiou, Rheology and thermodynamics in partially miscible polymer blends, J. Non-Newtonian Fluid Mech. 67 (1996) 191-212. 
[4] M. Alcoutlabi, G.B. McKenna, Effects of confinement on material behaviour at the nanometre size scale, J. Phys.: Condens. Matter 17 (2005) R461-R524.

[5] G. Luengo, F.-J. Schmitt, R. Hill, J. Israelachvili, Thin film rheology and tribology of confined polymer melts: contrasts with bulk properties, Macromolecules 30 (1997) 2482-2494.

[6] M. Ponting, A. Hiltner, E. Baer, Polymer nanostructures by forced assembly: Process, structure, and properties, Macromol. Symp. 294 (2010) 19-32.

[7] S. Thomas, R. Shanks, S. Chandrasekharakurup, Preface, Nanostructured Polymer Blends, William Andrew Publishing, Oxford, 2014, pp. Xv-Xvi.

[8] C.M. Bates, M.J. Maher, D.W. Janes, C.J. Ellison, C.G. Willson, Block copolymer lithography, Macromolecules 47 (2013) $2-12$.

[9] C. Sinturel, F.S. Bates, M.A. Hillmyer, High $\chi$-low N block polymers: how far can we go?, ACS Macro Lett 4 (2013) 1044-1050.

[10] G.H. Hu, H. Cartier, C. Plummer, Reactive extrusion: toward nanoblends, Macromolecules 32 (1999) 4713-4718.

[11] C.J. Sheehan, A.L. Bisio, Polymer/solvent interaction parameters, Rubber. Chem. Technol. 39 (1966) 149-192.

[12] M. Tambasco, J.E.G. Lipson, J.S. Higgins, Blend miscibility and the Flory-Huggins interaction parameter: a critical examination, Macromolecules 39 (2006) 4860-4868.

[13] W. Guo, J.S. Higgins, Miscibility and kinetics of phase separation in polymer blends of tetramethyl-bisphenol-A polycarbonate and polystyrene, Polymer 31 (1990) 699-706.

[14] T. Kyu, D.S. Lim, Phase decomposition in blends of polycarbonate and isotactic poly(methyl methacrylate), Macromolecules 24 (1991) $3645-3650$.

[15] M. Rubinstein, R.H. Colby, Polymer Physics, Oxford University Press, Oxford, 2003.

[16] P.J. Flory, Thermodynamics of high polymer solutions, J. Chem. Phys. 10 (1942) 51-61.

[17] M.L. Huggins, Thermodynamics of solutions of high polymers, J. Am. Chem. Soc. 64 (1942) $1712-1719$.

[18] J. Dudowicz, K.F. Freed, Effect of monomer structure and compressibility on the properties of multicomponent polymer blends and solutions: 1. Lattice cluster theory of compressible systems, Macromolecules 24 (1991) 5076-5095.

[19] J. Dudowicz, K.F. Freed, J.F. Douglas, New patterns of polymer blend miscibility associated with monomer shape and size asymmetry, J. Chem. Phys. 116 (2002) 9983-9996.

[20] J. Dudowicz, M.S. Freed, K.F. Freed, Effect of monomer structure and compressibility on the properties of multicomponent polymer blends and solutions. 2. Application to binary blends, Macromolecules 24 (1991) 5096-5111.

[21] R. Dickman, C.K. Hall, Equation of state for chain molecules: continuous-space analog of flory theory, J. Chem. Phys. 85 (1986) $4108-4115$.

[22] K.F. Freed, J. Dudowicz, Lattice cluster theory for pedestrians: the incompressible limit and the miscibility of polyolefin blends, Macromolecules 31 (1998) 6681-6690.

[23] I.C. Sanchez, R.H. Lacombe, An elementary equation of state for polymer liquids, J. Polym. Sci. Polym. Lett. 15 (1977) $71-75$.

[24] F.S. Bates, G.H. Fredrickson, Conformational asymmetry and polymer-polymer thermodynamics, Macromolecules 27 (1994) $1065-1067$.

[25] J. Dudowicz, K.F. Freed, J.F. Douglas, Concentration fluctuations in miscible polymer blends: influence of temperature and chain rigidity, J. Chem. Phys. 140 (2014) 194901

[26] T.H. Russell, B.J. Edwards, B. Khomami, Characterization of the Flory-Huggins interaction parameter of polymer thermodynamics, Europhys. Lett. 108 (2014) 66003

[27] A.W. Bosse, J.F. Douglas, The osmotic virial formulation of the free energy of polymer mixing, J. Chem. Phys. 143 (2015) 104903.

[28] E. Helfand, Y. Tagami, Theory of the interface between immiscible polymers, J. Polym. Sci. B Polym. Lett. 9 (1971) $741-746$.

[29] E. Helfand, Y. Tagami, Theory of the Interface between Immiscible polymers. II., J. Chem. Phys. 56 (1972) $3592-3601$.

[30] C.C. Han, B.J. Bauer, J.C. Clark, Y. Muroga, Y. Matsushita, M. Okada, Q. Tran-cong, T. Chang, I.C. Sanchez, Temperature, composition and molecularweight dependence of the binary interaction parameter of polystyrene/poly(vinyl methyl ether) blends, Polymer 29 (1988) $2002-2014$.

[31] W.H. Stockmayer, H.E. Stanley, Light-scattering measurement of interactions between unlike polymers, J. Chem. Phys. 18 (1950) $153-154$.

[32] T. Shiomi, K. Kohno, K. Yoneda, T. Tomita, M. Miya, K. Imai, Thermodynamic interactions in the poly(vinyl methyl ether)-polystyrene system, Macromolecules 18 (1985) 414-419.

[33] T. Fukuda, M. Nagata, H. Inagaki, Light scattering from ternary solutions. 1. Dilute solutions of polystyrene and poly(methyl methacrylate), Macromolecules 17 (1984) 548-553.

[34] N.E. Weeks, F.E. Karasz, W.J. MacKnight, Enthalpy of mixing of poly(2,6-dimethyl phenylene oxide) and polystyrene, J. Appl. Phys. 48 (1977) 40684071.

[35] T. Nishi, T.T. Wang, Melting point depression and kinetic effects of cooling on crystallization in poly(vinylidene fluoride)-poly(methyl methacrylate) mixtures, Macromolecules 8 (6) (1975) 909-915.

[36] W.N. Kim, C.M. Burns, Blends of polycarbonate and poly(methyl methacrylate) and the determination of the polymer-polymer interaction parameter of the two polymers, Macromolecules 20 (1987) 1876-1882.

[37] L. Leibler, Theory of microphase separation in block copolymers, Macromolecules 13 (1980) 1602-1617.

[38] L. Leibler, Theory of phase equilibria in mixtures of copolymers and homopolymers. 2 . Interfaces near the consolute point, Macromolecules 15 (1982) 1283-1290.

[39] A.K. Dolan, S.F. Edwards, Theory of the stabilization of colloids by adsorbed polymer, Proc. R. Soc. Lond. A Math. Phys. Eng. Sci. 337 (1974) 509-516.

[40] E. Helfand, Theory of inhomogeneous polymers: fundamentals of the Gaussian random-walk model, J. Chem. Phys. 62 (1975) $999-1005$.

[41] G. Hadziioannou, R.S. Stein, Neutron scattering studies of dimensions and of interactions between components in polystyrene/poly(vinyl methyl ether) and poly(vinylidene fluoride)/poly(methyl methacrylate) amorphous blends, Macromolecules 17 (1984) $567-573$.

[42] C. Herkt-Maetzky, J. Schelten, Critical fluctuations in a binary polymer mixture, Phys. Rev. Lett. 51 (1983) 896-899.

[43] B. Stühn, The relation between the microphase separation transition and the glass transition in diblock copolymers, J. Polym. Sci. B Polym. Phys. 30 (1992) 1013-1019.

[44] I.C. Sanchez, Relationships between polymer interaction parameters, Polymer 30 (1989) 471-475.

[45] H.R. Travis, J.E. Brian, K. Bamin, Characterization of the Flory-Huggins interaction parameter of polymer thermodynamics, Europhys. Lett. 108 (2014) 66003.

[46] E. Helfand, A.M. Sapse, Theory of unsymmetric polymer-polymer interfaces, J. Chem. Phys. 62 (1975) $1327-1331$.

[47] F. Saulnier, Dynamic processes at polymeric interfaces Thesis, Université Pierre et Marie Curie, Paris VI, 2003.

[48] D. Broseta, G.H. Fredrickson, E. Helfand, L. Leibler, Molecular weight and polydispersity effects at polymer-polymer interfaces, Macromolecules 23 (1990) $132-139$.

[49] T.A. Callaghan, D.R. Paul, Interaction energies for blends of poly(methyl methacrylate), polystyrene, and poly(alpha-methylstyrene) by the critical molecular weight method, Macromolecules 26 (1993) 2439-2450.

[50] P. Xing, M. Bousmina, D. Rodrigue, M.R. Kamal, Critical experimental comparison between five techniques for the determination of interfacial tension in polymer blends: model system of polystyrene/polyamide-6, Macromolecules 33 (2000) 8020-8034.

[51] J.H. Hildebrand, R.L. Scott, The Solubility of Nonelectrolytes, Reinhold Pub. Corp., New York, 1950. 488 p.

[52] D.W. Van Krevelen, K. Te Nijenhuis, Chapter 8 - interfacial energy properties, in: Properties of Polymers, 4th ed., Elsevier, Amsterdam, 2009, pp. 229244.

[53] C.M. Hansen, Hansen Solubility Parameters: A User’s Handbook, 2nd ed., CRC Press, 2007.

[54] A.F.M. Barton, Applications of solubility parameters and other cohesion parameters in polymer science and technology, Pure. Appl. Chem. 57 (1985) $905-912$.

[55] E. Stefanis, C. Panayiotou, A new expanded solubility parameter approach, Int. J. Pharm. 426 (2012) $29-43$.

[56] J.E. Mark, Physical Properties of Polymers Handbook, Springer, 2006.

[57] L.A. Utracki, R. Simha, Statistical thermodynamics predictions of the solubility parameter, Polym. Int. 53 (2004) $279-286$.

[58] R. Simha, T. Somcynsky, On the statistical thermodynamics of spherical and chain molecule fluids, Macromolecules 2 (1969) $342-350$. 
[59] C. Panayiotou, Polymer-polymer miscibility and partial solvation parameters, Polymer 54 (2013) 1621-1638.

[60] C. Panayiotou, Redefining solubility parameters: the partial solvation parameters, Phys. Chem. Chem. Phys. 14 (2012) $3882-3908$.

[61] A. Dobry, F. Boyer-Kawenoki, Phase separation in polymer solution, J. Polym. Sci. 2 (1947) 90-100.

[62] R.L. Scott, The thermodynamics of high polymer solutions. V. Phase equilibria in the ternary system: polymer 1-polymer 2-solvent, J. Chem. Phys. 17 (1949) 279-284.

[63] T.P. Russell, R.P. Hjelm, P.A. Seeger, Temperature dependence of the interaction parameter of polystyrene and poly(methyl methacrylate), Macromolecules 23 (1990) 890-893.

[64] T.P. Russell, Changes in polystyrene and poly(methyl methacrylate) interactions with isotopic substitution, Macromolecules 26 (1993) 5819. 58195819.

[65] We would also like to point out here that these values are reported by Balsara in Ref. [56]. Mark, J.E., Physical Properties of Polymers Handbook. Springer: 2006. and also in Ref. [15]. Rubinstein, M.; Colby, R.H., Polymer physics. Oxford University Press: Oxford, 2003) under a different form: the values are normalized for a monomer volume of $0.1 \mathrm{~nm}^{3}$ while the average monomer volume for PS and PMMA is 0.163 nm ${ }^{3}$ according to the same source. Thus the values reported by Balsara are different (1.63 times smaller) than the actual values from Russell, which could lead to mistakes from the inattentive reader.

[66] R.P. White, J.E.G. Lipson, J.S. Higgins, Effect of deuterium substitution on the physical properties of polymer melts and blends, Macromolecules 43 (2010) 4287-4293.

[67] W.W. Maurer, F.S. Bates, T.P. Lodge, K. Almdal, K. Mortensen, G.H. Fredrickson, Can a single function for $\chi$ account for block copolymer and homopolymer blend phase behavior?, J Chem. Phys. 108 (1998) 2989-3000.

[68] Y. Zhao, E. Sivaniah, T. Hashimoto, SAXS analysis of the order-disorder transition and the interaction parameter of polystyrene-block-poly(methyl methacrylate), Macromolecules 41 (2008) 9948-9951.

[69] Other extrapolation methods (leading to somewhat smaller - around 20\% - values) are discussed in the article but Callaghan and Paul claimed the binary interaction model should provide the best estimate.

[70] M.L. Fernandez, J.S. Higgins, J. Penfold, R.C. Ward, C. Shackleton, D.J. Walsh, Neutron reflection investigation of the interface between an immiscible polymer pair, Polymer 29 (1988) 1923-1928.

[71] R.J. Composto, E.J. Kramer, D.M. White, Mutual diffusion in the miscible polymer blend polystyrene/poly(xylenyl ether), Macromolecules 21 (1988) $2580-2588$.

[72] C. Hu, X. Chen, J. Chen, W. Zhang, M.Q. Zhang, Observation of mutual diffusion of macromolecules in PS/PMMA binary films by confocal Raman microscopy, Soft Matter 8 (2012) 4780-4787.

[73] J.P. Tomba, Comment on "Observation of mutual diffusion of macromolecules in PS/PMMA binary films by confocal Raman microscopy" by C. Hu, X. Chen, J. Chen, W. Zhang, M.Q. Zhang, Soft Matter, 2012, 8, 4780, Soft Matter 12 (2016) 4510-4513.

[74] S. Wu, Surface and interfacial tensions of polymer melts. II. Poly(methyl methacrylate), poly(n-butyl methacrylate), and polystyrene, J Phys Chem 74 (1970) 632-638.

[75] J.C. Carriere, G. Biresaw, L.R. Sammler, Temperature dependence of the interfacial tension of PS/PMMA, PS/PE, and PMMA/PE blends, Rheol. Acta 39 (2000) 476-482.

[76] H. Tang, K.F. Freed, Interfacial studies of incompressible binary blends, J. Chem. Phys. 94 (1991) 6307-6322.

[77] S.H. Anastasiadis, T.P. Russell, S.K. Satija, C.F. Majkrzak, Neutron reflectivity studies of the surface-induced ordering of diblock copolymer films, Phys. Rev. Lett. 62 (1989) 1852-1855.

[78] D.G.H. Ballard, G.D. Wignall, J. Schelten, Measurement of molecular dimensions of polystyrene chains in the bulk polymer by low angle neutron diffraction, Eur. Polym. J. 9 (1973) 965-969.

[79] V.R.G. Kirste, Neue vorstellungen über statistische fadenknäuel, Makromol. Chem. 101 (1967) 91-103.

[80] L.J. Fetters, D.J. Lohse, D. Richter, T.A. Witten, A. Zirkel, Connection between polymer molecular weight, density, chain dimensions, and melt viscoelastic properties, Macromolecules 27 (1994) 4639-4647.

[81] J. Brandrup, E.H. Immergut, E.A. Grulke, Polymer Handbook, 4th ed., Wiley, 2003.

[82] G.M. Bristow, W.F. Watson, Cohesive energy densities of polymers. Part 2. - Cohesive energy densities from viscosity measurements, Trans. Faraday Soc. 54 (1958) 1742-1747.

[83] P.A. Small, Some factors affecting the solubility of polymers, J. Appl. Chem. 3 (1953) 71-80.

[84] It is not clear how these values are measured since the reference in Hansen's Handbook concerning these data is the Hansen's Handbook itself

[85] W.N. Kim, C.M. Burns, Phase behavior of blends of polycarbonate with partially miscible polymers, J. Appl. Polym. Sci. 41 (1990) $1575-1593$.

[86] J. Kolarik, F. Lednicky, B. Pukanszky, M. Pegoraro, Blends of polycarbonate with poly(methyl methacrylate): miscibility, phase continuity, and interfacial adhesion, Polym. Eng. Sci. 32 (1992) 886-893.

[87] T.A. Callaghan, D.R. Paul, Estimation of interaction energies by the critical molecular weight method: 1. Blends with polycarbonates, J. Polym. Sci. B Polym. Phys. 32 (1994) 1813-1845.

[88] Note that Callaghan and Paul used for reference volume $212.4 \mathrm{~cm}^{3} / \mathrm{mol}$, stated as the volume of the repeating unit for the PC.

[89] C.J. Carriere, A. Cohen, Evaluation of the interfacial tension between high molecular weight polycarbonate and PMMA resins with the imbedded fiber retraction technique, J. Rheol. 35 (1991) 205-212.

[90] S. Wu, Chain structure and entanglement, J. Polym. Sci. B Polym. Phys. 27 (1989) 723-741.

[91] W.N. Kim, C.M. Burns, Thermal behavior, morphology, and the determination of the Flory-Huggins interaction parameter of polycarbonatepolystyrene blends, J. Appl. Polym. Sci. 34 (1987) 945-967.

[92] G.D. Butzbach, J.H. Wendorff, Polycarbonate-poly(methyl methacrylate) blends: the role of molecular interactions on miscibility and antiplasticization, Polymer 32 (1991) 1155-1159.

[93] T. Kyu, J.M. Saldanha, Miscible blends of polycarbonate and polymethyl methacrylate, J. Polym. Sci. C Polym. Lett. 26 (1988) 33-40.

[94] R.Y.F. Liu, T.E. Bernal-Lara, A. Hiltner, E. Baer, Polymer interphase materials by forced assembly, Macromolecules 38 (2005) $4819-4827$.

[95] S. Roland, G. Miquelard-Garnier, M. Gervais, A. Guinault, C. Sollogoub, Controlling the order of triblock copolymer via confinement induced by forced self-assembly, Mater. Today Commun. 6 (2016) 37-43. 